\title{
ASSOCIATION BETWEEN THE SEROTONIN TRANSPORTER GENE AND AFFECTIVE DISORDER: THE EVIDENCE SO FAR
}

\author{
Alan D. Ogilvie and Anthony J. Harmar \\ MRC Brain Metabolism Unit, Royal Edinburgh Hospital, Morningside \\ Park, Edinburgh, United Kingdom
}

The serotonin transporter is one of a family of sodium-dependent monoamine transporters, which includes those for norepinephrine, dopamine, glycine, and GABA. Many antidepressant agents function by inhibiting the serotonin transporter, and the highly effective serotonin selective reuptake inhibitors (SSRIs), such as fluoxetine (Prozac), do so very specifically. In 1996 molecular genetic studies demonstrated an association between allelic variation in the gene for the serotonin transporter and susceptibility to affective disorder (depression and manic depressive illness), and they suggested that this gene may be important in determining the inheritance of certain "normal" personality traits, most notably, those grouped under the heading "neuroticism." In addition, the molecular biology of regulation of the serotonin transporter gene is beginning to be unravelled.

\section{DYSFUNCTION OF THE SEROTONERGIC SYSTEM IN AFFECTIVE DISORDER}

The serotonin transporter is a member of a very ancient family of proteins present in organisms ranging from bacteria to humans. Primitive members of this protein family probably evolved to enable cells to accumulate metabolically important small molecules or to respond to osmotic

Address correspondence and reprint requests to: Alan D. Ogilvie, University of Cambridge, Dept. of Psychiatry, Addenbrooke's Hospital, Hills Road, Cambridge CB2 2QQ, United Kingdom. stress by intracellular accumulation of high concentrations of small organic solutes (osmolytes) in exchange for inorganic ions (electrolytes). In brain, similar proteins fulfill the more specialized function of terminating the action of neurotransmitters by removing them from the synaptic cleft and recycling them into the neurotransmitter pool.

The evidence for dysfunction of the serotonergic system in affective disorder is compelling. Levels of the serotonin metabolite 5-hydroxyindoleacetic acid (5-HIAA) are decreased in depressed patients, especially those likely to commit suicide (reviewed in ref. 1). There is also evidence for reduced plasma levels of tryptophan, the amino acid precursor of serotonin, in depression $(2,3)$, and tryptophan depletion causes a lowering of mood in normal subjects and in recovered depressed patients (4). In addition, withdrawal of L-tryptophan treatment appears to precipitate relapse in chronically depressed patients (5). Reports of abnormalities in the binding sites for imipramine in blood platelets and brain of patients $(6,7)$ suggest altered function and/or regulation of the serotonin transporter in affective disorder. Imipramine was one of the first drugs used to effectively treat depressive illness $(8,9)$. It is a tricyclic antidepressant that nonselectively inhibits the uptake of norepinephrine and serotonin. Serotonin selective reuptake inhibitors (SSRIs) such as fluvoxamine, fluoxetine, and paroxetine target the serotonin transporter specifically. These drugs were developed in a successful strategy to retain the efficacy of the tricyclic compounds, while reducing side effects and toxicity (10). 


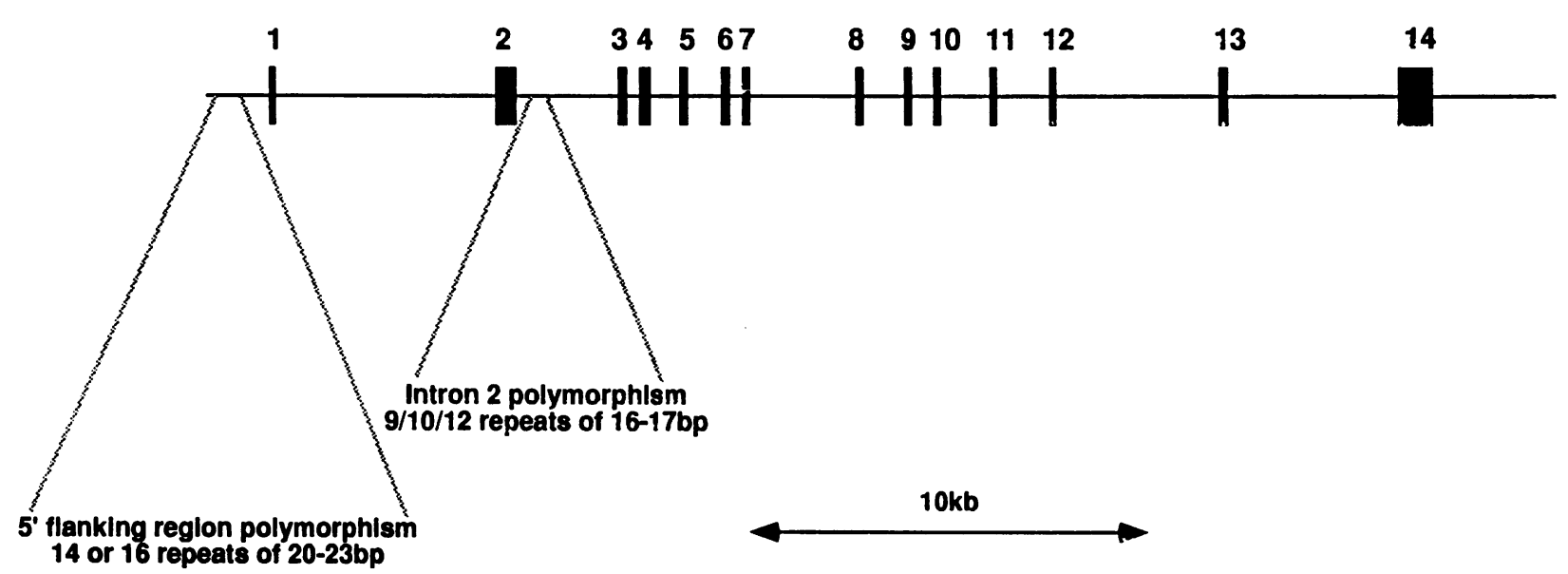

FIG. 1. Structure of the polymorphic regions of the serotonin transporter gene $(14,15,21)$

\section{GENETIC VARIATION IN THE SEROTONIN TRANSPORTER}

Following the cloning of the cDNA $(11,12)$ encoding the human serotonin transporter, Lesch and colleagues (13) examined its primary structure in patients with affective disorder. Sequencing of the protein coding region failed to reveal changes in the deduced amino acid sequence, and only one base substitution, representing a silent polymorphism, was found in a single patient. Subsequent studies have focused on the role of polymorphisms in noncoding regions of the gene in the etiology of affective and related psychiatric disorders and in determining normal personality traits that may contribute to susceptibility to these disorders.

\section{Polymorphism in Intron 2}

The first polymorphic region described was a variable number tandem repeat (VNTR) in the second intron of the gene (14) that contains 9, 10 , or 12 copies of a $16-17$ bp motif (15) (Fig. 1). Although one report suggested that different allelic forms may exist in a non-Caucasian (Japanese) population (16), subsequent sequencing has not confirmed this (Battersby, Kunugi, Ogilvie et al., unpublished results). Several studies have now demonstrated an association between allelic forms at this locus and susceptibility to unipolar and to bipolar disorder. We have demonstrated an association between the rare 9 repeat form of the VNTR and risk of both unipolar (15) and bipolar disorder (17) in a Scottish population. This association was not found in German (18) or Japanese (16) patients, but subse- quent studies have found an increased frequency of the 12 repeat allele in patients with bipolar disorder $(19,20)$ in independent samples. This is also the case when the Japanese data is reconsidered in light of the correct sequence data (16). It is not clear whether allelic variation at this VNTR may directly influence expression of the transporter in the central nervous system (CNS) or whether this polymorphism is in linkage disequilibrium with a nearby locus of importance.

\section{Polymorphism in the 5' Flanking Region}

The second polymorphism of interest lies $1.2 \mathrm{~kb}$ upstream of the promoter of the gene where two relatively common allelic forms (528 bp "long" and 484 bp "short") of a GC-rich repetitive sequence have been described (21) (Fig. 1). In vitro studies of the functional effects of this polymorphism in the context of the serotonin transporter promoter showed that the long variant is associated with a 3-fold higher transcriptional activity and increased responsiveness to stimulation by forskolin or phorbol ester. The long variant is also significantly more potent in repressing transcriptional activity when fused to a heterologous promoter. Serotonin transporter mRNA levels and serotonin uptake capacity were reduced in lymphoblastoid cell lines derived from individuals with one or two copies of the short allele compared with those from long homozygotes (22). A recent report (23) has shown that the short variant of the polymorphic region was significantly more frequent in patients with bipolar and unipolar affective disorder, which suggests that the polymorphism may have functional 
consequences. In addition, it has been reported (24) that allelic variation at this locus correlates with anxiety-related personality traits, which may in turn be associated with increased risk of affective disorder (25). It thus remains to be established whether this locus directly predisposes a person to affective disorder or does so indirectly, mediating its effect by personality factors.

\section{FUTURE DIRECTIONS}

In summary, there is evidence to suggest that, in a subgroup of patients, a locus within or close to the serotonin transporter gene may predispose to affective disorder, either directly or as a consequence of its effect on personality. There are two possible mechanisms that may explain the association between the two polymorphisms described above and the risk of affective disorder. It is possible that the level of serotonin transporter gene transcription may be influenced by the sequences of the repetitive elements in either or both of the polymorphic regions. Alternatively, they may be in linkage disequilibrium with another, more directly relevant gene locus. The fact that different allelic forms of the intron-2 polymorphism appear to be associated with affective disorder in different populations suggests linkage dysequilibrium with a nearby locus of biological significance. To assess the importance of the $5^{\prime}$ polymorphic region, studies of its influence on the expression and regulation of the serotonin transporter gene in human subjects are required. Although it is clearly important to unravel the biological consequences of these two polymorphisms, it is also plausible that the locus of importance lies elsewhere in the region. More detailed analysis of this region may ultimately yield findings of great interest.

\section{REFERENCES}

1. Meltzer HY, Lowy MT. (1987) The serotonin hypothesis of depression. In: Meltzer $\mathrm{H}$ (eds.) Psychopharmacology, the Third Generation of Progress. Raven Press, New York.

2. Coppen A, Wood K. (1978) Tryptophan and depressive illness. Psychol. Med. 8: 49.

3. DeMeyer MK, Shea PA, Hendrie HC, Yoshimura NN. (1981) Plasma tryptophan and five other amino acids in depressed and normal subjects. Arch. Gen. Psychiatry 38: 642-646.

4. Salomon RM, Miller HL, Delgado PL, Char- ney D. (1993) The use of tryptophan depletion to evaluate central serotonin function in depression and other neuropsychiatric disorders. Int. Clin. Psychopharmacol. 8: 41-46.

5. Ferrier IN, Eccelston D, Moore PB, Wood KA. (1990) Relapse in chronic depressives on withdrawal of 1-tryptophan. Lancet 336: 380-381.

6. Boyer WF, Feighner JP. (1991) The serotonin hypothesis: Necessary but not sufficient. In: Feighner JP Boyer WF (eds.) Selective Serotonin Re-uptake Inhibitors. John Wiley $\mathcal{G}$ Sons, Chichester, pp. 71-80.

7. Maj M. (1988) Changes in platelet ${ }^{3} \mathrm{H}$-imipramine binding in depressed patients receiving electroconvulsive therapy. Biol. Psychiatry 24: 469.

8. Kuhn R. (1958) The treatment of depressive states with G22355 (imipramine hydrochloride). Am. J. Psychiatry 115: 459-464.

9. Davis JM, Glassman AH. (1989) Antidepressant drugs. In: Kaplan HI Sadock BJ (eds) Compressive Textbook of Psychiatry. Williams \& Wilkins, Baltimore, pp. 1627-1655.

10. Anderson IM, Tomenson BM. (1994) The efficacy of selective serotonin re-uptake inhibitors in depression: A meta-analysis of studies against tricyclic antidepressants. J. Psychopharmacol. 8: 238-249.

11. Lesch KP, Wolozin BL, Estler HC, Murphy DL, Riederer P. (1993) Isolation of a cDNA encoding the human brain serotonin transporter. J. Neural Trans. Gen. Sec. 91: 67-72.

12. Ramamoorthy S, Bauman AL, Moore KR, et al. (1993) Antidepressant- and cocaine-sensitive human serotonin transporter: Molecular cloning, expression, and chromosomal localization. Proc. Natl. Acad. Sci. U.S.A. 90: 2542-2546.

13. Lesch KP, Gross J, Franzek E, Wolozin BL, Riederer P, Murphy DL. (1995) Primary structure of the serotonin transporter in unipolar depression and bipolar disorder. Biol. Psychiatry 37: 215-223.

14. Lesch KP, Balling U, Gross J, et al. (1994) Organization of the human serotonin transporter gene. J. Neural Transm. Gen. Sect. 95: 157-162.

15. Ogilvie $A D$, Battersby $S, B u b b \mathrm{VJ}$, et al. (1996) A polymorphism of the serotonin transporter gene is associated with susceptibility to major affective disorder. Lancet 347: 731-733.

16. Kunugi H, Tatsumi $M$, Sakai T, Hattori $M$, Nanko S. (1996) Serotonin transporter gene 
polymorphism and affective disorder. Lancet 347: $1340-1340$.

17. Battersby S, Ogilvie AD, Smith CAD, et al. (in press) Structure of a VNTR of the serotonin transporter gene and association with affective disorder. Psychiatr. Genet. (in press).

18. Stober G, Heils A, Lesch KP. (1996) Serotonin transporter gene polymorphism and affective disorder. Lancet 347: 1340-1341.

19. Collier DA, Stoeber G, Li T, et al. (1996) A novel functional polymorphism within the promoter of the serotonin transporter gene: a possible role in susceptibility to affective disorders. Mol. Psychiatry 1: 453-460.

20. Collier DA, Arranz MJ, Sham P, et al. (1996) The serotonin transporter gene is a potential susceptibility factor for bipolar affective disorder. Neurocase 7: 1675-1679.

21. Heils A, Teufel A, Petri S, et al. (1996) Allelic variation of human serotonin transporter gene expression. J. Neurochem. 66: 26212624.

22. Lesch KP, Bengel D, Heils A, et al. (1996) Association of anxiety related traits with a polymorphism in the serotonin transporter gene. Science 274: 1527-1531.

23. Collier DA, Stober G, Li T, et al. (1996) Susceptibility to bipolar affective disorders and unipolar depression is influenced by allelic variation of functional serotonin transporter expression. Psychiatr. Genet. 6: 147.

24. Greenberg BD, Hamer D, Benjamin J, et al. (1996) Association between anxiety-related personality features and a regulatory region polymorphism which alters expression of the serotonin transporter. Am. J. Hum. Genet. 59: A219.

25. Jardine R, Martin NG, Henderson AS. (1984) Genetic covariation between neuroticism and the symptoms of anxiety and depression. Genet. Epidemiol. 1: 89-107. 